\title{
Visualization and manipulation of neural activity in the developing vertebrate nervous system
}

\author{
Jiayi Zhang ${ }^{\dagger}$, James B. Ackman ${ }^{\dagger}$, Onkar S. Dhande and Michael C. Crair *
}

Department of Neurobiology, Yale University, New Haven, CT, USA

Edited by:

Alistair N. Garratt, Max Delbrück

Center for Molecular Medicine,

Germany

\section{Reviewed by:}

Peer Wulff, University of Aberdeen, UK

Ye He, University of California San

Francisco, USA

\section{*Correspondence:}

Michael C. Crair, Yale University

School of Medicine, 333 Cedar

Street, SHM B301, New Haven, CT

06510, USA.

e-mail: michael.crair@yale.edu

† Jiayi Zhang and James B. Ackman

have contributed equally to this work.
Neural activity during vertebrate development has been unambiguously shown to play a critical role in sculpting circuit formation and function. Patterned neural activity in various parts of the developing nervous system is thought to modulate neurite outgrowth, axon targeting, and synapse refinement. The nature and role of patterned neural activity during development has been classically studied with in vitro preparations using pharmacological manipulations. In this review we discuss newly available and developing molecular-genetic tools for the visualization and manipulation of neural activity patterns specifically during development.

Keywords: optogenetics, development, neuron, circuit, vision, imaging

\section{INTRODUCTION}

Neural circuits are assembled with a high degree of precision and stereotypy in the developing brain. One of the major goals that neuroscientists have long sought is to understand the principles and factors that govern the emergence of these precise connectivity patterns. The conventional model of nervous system development posits the requirement of both genetic and molecular cues in conjugation with neural activity and sensory experience to sculpt neural circuits. Neural connections are plastic and can be sharpened and tuned by sensory experience, particularly during what has been termed "critical periods" in development (Katz and Shatz, 1996). However, the connections within and between different brain regions are established predominantly before mammals are capable of perceiving sensory input. During this period spontaneous network activity is present throughout multiple regions of the brain such as the cortex, spinal cord, cerebellum, hippocampus, and retina. The spatial and temporal structure, developmental onset, and progression as well as cellular and molecular mechanisms of spontaneous network activity in developing neural circuits has been an area of intense investigation over the past two decades (Feller, 1999; O’Donovan, 1999; Spitzer, 2006; Blankenship and Feller, 2010). Although much is known about the mechanisms underlying the origin and functional role of spontaneous network activity in regulating formation of precise network connections, almost all studies that have tackled these questions have relied on in vitro or reduced in vivo preparations. Little is known about the nature or consequence of altering the spatiotemporal properties of patterned neural activity in an intact in vivo setting in mammalian systems.

In the last decade we have seen the advent of new and innovative technologies that enable neuroscientists to image and alter the activity of neural networks in vivo. Though many of the existing techniques have been applied to study adult network connectivity and function, their utilization in exploring the role of activity-dependent circuit formation during development has been lacking. Visualization and manipulation of network activity in developing mammalian circuits in vivo presents unique challenges due to the difficulties in accessing various neural structures without invasive surgery, availability of appropriate techniques due to dynamic changes in gene expression during development, and the difficulties of working with embryonic and early postnatal animals. In this review we discuss some of the current and emerging technologies that allow us to probe and manipulate neural activity on a cellular or network level and understand how such activities contribute to maturation of neural connectivity and function. We also discuss the drawbacks and constraints of various methods when applied to the studies of the developing brain.

\section{VISUALIZING NEURAL ACTIVITY}

The first optical recordings of neuronal activity were obtained over 60 years ago from invertebrate motor nerve using a stimulating electrode, a tungsten lamp, and a photocell (Hill and Keynes, 1949). Currently, laser scanning microscopy together with fluorescent dyes and genetically engineered optical sensors enables neuroscientists to obtain recordings from hundreds of neurons simultaneously with subcellular resolution in awake, behaving mice (Greenberg et al., 2008; Dombeck et al., 2009; Andermann et al., 2010; Lütcke et al., 2010). Given the many advances made in optical imaging and molecular genetics methodologies for systems neuroscience, we discuss here some of the technologies available to developmental neurobiologists for recording from neuronal populations optically during neural circuit formation. 


\section{VOLTAGE-SENSITIVE DYE IMAGING}

The original optical recordings of neuronal activity were based on light scattering and absorptive changes intrinsic to neural tissue during excitation (Cohen et al., 1968; Tasaki et al., 1968; von Muralt, 1975) or fluorescence changes in dyes sensitive to membrane potential (Davila et al., 1973; Cohen et al., 1978). These imaging techniques based on intrinsic optical or voltage-sensitive dye (VSD) signals have provided elegant methods for assessing the large-scale topographic organization of sensory maps in the vertebrate olfactory bulb (Orbach and Cohen, 1983; Kauer, 1988; Rubin and Katz, 1999; Spors and Grinvald, 2002), optic tectum (Grinvald et al., 1984), and cerebral cortex (Orbach et al., 1985; Lieke et al., 1989; Ts'o et al., 1990; Bonhoeffer and Grinvald, 1991). The ability of intrinsic signal imaging to non-invasively provide functional sensory maps resolved to distances of $50-100 \mu \mathrm{m}$ has been utilized with much success in studies of the activity-dependent development of circuits underlying retinotopy, orientation selectivity, and ocular dominance segregation in the mammalian visual system (Chapman et al., 1996; Crair et al., 1998; Cang et al., 2005; Mrsic-Flogel et al., 2005). Since VSDs directly measure membrane potential, their rapid millisecond time course has made VSDs the best optical method for mapping the emergence of neural activity in response to evoked stimulation with high temporal resolution at the subcellular (Djurisic et al., 2004) or population levels (Grinvald and Hildesheim, 2004). Traditionally, the signal-to-noise ratio within intact tissue for both intrinsic and VSD imaging has been very low, such that single trial experiments and spontaneous activity recordings were impracticable (Sjulson and Miesenböck, 2007). However, VSDI has been used for recording highly synchronized population events such as those occurring during spontaneous seizures (Orbach et al., 1985; Sutor et al., 1994) and the intrinsic optical signals associated with spontaneous activity in the developing rat cochlea has been documented (Tritsch et al., 2007). Furthermore, the latest generation of red shifted VSDs (Shoham et al., 1999; Spors and Grinvald, 2002) can produce fractional signals large enough for single trial exploration of spontaneous activities with unprecedented spatiotemporal resolution in the neocortex in vivo (Ferezou et al., 2006; Benucci et al., 2007; Xu et al., 2007; Han et al., 2008). Currently, a major limitation in the use of VSDs for recording population activity in neural circuits is the non-specific staining of cellular elements in the neuropil of intact tissue. Thus the measured signals with VSDs in bulk labeled tissue are summed signals from unidentified cellular constituents, precluding their use in recording from neuronal ensembles with multicellular resolution.

\section{CALCIUM SENSITIVE DYE IMAGING}

The development of fluorescent calcium indicators in the 1980s (Tsien, 1989) gave neuroscientists a method for measuring the rapid changes in calcium concentration that occurs as a result of membrane depolarization (Regehr et al., 1989). Bulk application of membrane permeable forms of calcium indicators to brain slices (Yuste and Katz, 1991) or cerebral cortex in vivo (Stosiek et al., 2003) allows for monitoring calcium changes in hundreds of identifiable neurons simultaneously because these ester dyes are largely non-fluorescent in the extracellular space. The fractional fluorescent signals in response to calcium binding to these indicators is large compared with VSDs (Cossart et al., 2005) and simultaneous current clamp recordings have demonstrated that the measured change in fluorescence of bulk loaded calcium dyes at the neuronal soma reflects action potential output in vitro (Smetters et al., 1999) and in vivo (Kerr et al., 2005). Multiphoton microscopy combined with calcium imaging has been used to assess the network dynamics of 10-100 s of neurons simultaneously in neocortical brain slices (Cossart et al., 2003; Ikegaya et al., 2004) and measure spontaneous (Stosiek et al., 2003) and evoked (Ohki et al., 2005) neuronal activity in vivo. Multineuron calcium imaging has been used for understanding the mechanisms underlying periodic spontaneous oscillations in developing neocortex (Yuste et al., 1995; Garaschuk et al., 2000; Allene et al., 2008), hippocampus (Crépel et al., 2007; Bonifazi et al., 2009), and has been used to study the altered neuronal networks present in a rodent model of a human cortical malformation disorder (Ackman et al., 2009).

Studies utilizing these optical recording methods have yielded insights into neural network function previously unattainable using traditional neurophysiological methods. However care must be taken when interpreting results from any studies using these techniques. Dye based imaging techniques require invasive introduction of the fluorescent indicator into the circuits of interest. Calcium imaging with multicellular resolution presents inherent technical limitations with respect to temporal resolution. Though voltage dye based imaging can have high temporal resolution, bulk loading of the indicator is typically limited to tissue surfaces and does not achieve cellular resolution. The ability to optically detect single spikes can always be an issue with these techniques. However, discrimination of single spikes may be of less interest in some developmental studies, as it is hypothesized that many aspects of synapse refinement during early development are governed by burst timing dependent plasticity rules (Butts et al., 2007; Gjorgjieva et al., 2009). This indicates that simply detecting spike bursts as commonly seen in large amplitude calcium transients might be a sufficient amount of temporal resolution for some studies of activity-dependent development.

\section{GENETIC REPORTERS OF NEURAL ACTIVITY}

In recent years, genetic based reporters of neural activity have undergone significant development. The first generations of genetically encodable calcium indicators (GECI) utilizing calmodulinM13 (Miyawaki et al., 1997) and troponin-C (Heim and Griesbeck, 2004) were Förster resonance energy transfer (FRET) based optical sensors. Sensors based on these reporters have been used to successfully study sensory evoked patterns in organisms such as $C$. elegans, drosophilia, and zebrafish (Kerr et al., 2000; Higashijima et al., 2003; Wang et al., 2003; Chalasani et al., 2007; Jayaraman and Laurent, 2007). These genetic calcium reporters were sufficient for evoked activity patterns averaged over many trials, but the dye signals were often insufficient for detecting single AP events or spontaneous activities. In addition to the sensitivity problem, in mammals the expression levels have been difficult to get high enough for routine use of these GECI. Recently, improvements have been made with the most recent generation of calcium indicators. Transgenic mice expressing GCaMP2 have been useful for studying odor evoked calcium activity in the olfactory bulb 
(Chaigneau et al., 2007; Fletcher et al., 2009), as well as transients in the cerebellum (Díez-García et al., 2007). Viral vectors expressing the recently made TN-XXL (Heim et al., 2007), YC3.60 (Nagai et al., 2004), GCaMP2 (Tallini et al., 2006), or GCaMP3 (Tian et al., 2003) have been used for optical recordings in neuronal networks in the neocortex (Mank et al., 2008; Kuchibhotla et al., 2009; Andermann et al., 2010; Lütcke et al., 2010), olfactory, bulb, and cerebellum. These newest generation GECIs, together with appropriate cell-specific promoters and viral transduction methodologies, allows high enough expression levels to monitor ongoing neural activity in defined populations of neurons, even in mammals.

In addition, genetically encodable voltage sensors have undergone significant development in recent years (Knöpfel et al., 2010). The latest generations of VSFPs are sensitive enough to detect single AP evoked depolarizations, as well as ongoing spontaneous activity. Further technical improvements will allow for reliable optical recording of both subthreshold and suprathreshold neural activity in neuronal populations using VSFPs.

\section{IMMEDIATE EARLY GENE REPORTERS}

Another technique for visualizing active neuronal ensembles is to image activity-dependent transcription or translation products from immediate early genes (IEGs). IEGs such as Arc/Arg3.1, c-fos, Nr4a1, Homer 1a, junB, and zif268 undergo transcriptional and translational activation in response to recent bouts of neuronal activity (Flavell and Greenberg, 2008; Loebrich and Nedivi, 2009) and play a key role in orchestrating multiple aspects of synaptic plasticity. For example, a burst of Arc expression is observed in the nuclei of rat hippocampal neurons within 2 min after a behavioral stimulus has been given and the number of cells with intense Arc+ nuclei declines back to baseline levels within $16 \mathrm{~min}$ of stimulus cessation (Guzowski et al., 2005). Arc/Agr3.1 has been demonstrated to undergo translation after just $5 \mathrm{~min}$ of enhanced neuronal activity. Though transcription and translation of these genes cannot follow the activity of neurons in real time, experiments in the hippocampus have demonstrated that their enriched expression is limited to those cell assemblies that have been utilized in recent experience, such as spatial memory networks in the hippocampus. Several transgenic mice with IEG based reporters have been created that allow targeted imaging of active neurons. For example, fosGFP mice have been used to illustrate networks of interconnected neurons in barrel cortex with elevated spontaneous firing (Yassin et al., 2010). In vivo time lapse imaging in Arc-GFP knock-in mice can be used to distinguish different groups of neurons in visual cortex that are activated by different recently experienced stimulus orientations in the visual field (Wang et al., 2006). Furthermore, infusion of a prodrug, Daun02 into $c$-fos-lacZ transgenic rats leads to conversion of the prodrug by $\beta$-galactosidase into daunorubicin, a $\mathrm{Ca}^{2+}$-dependent action potential inhibitor, thus making the selective inactivation of recently active neuronal assemblies possible (Koya et al., 2009; Bossert et al., 2011).

\section{TECHNICAL CONSIDERATIONS FOR DEVELOPMENTAL STUDIES}

There are several methodological issues to consider when using genetic calcium or voltage-sensitive reporters for studies of neural development. One issue is achieving suitable levels of reporter expression. In all organisms, careful choice of cell-specific promoters or recombination strategy is important for ensuring expression of a GECI or VSFPs with correct spatiotemporal patterns, since dynamic changes in gene transcription occurs during development. For example, stable expression in subsets of cells such as interneurons should be possible, though some cell-specific markers are not expressed until relatively late in development (e.g., three postnatal weeks for parvalbumin, a marker for fast-spiking interneurons). Thyl has been a very useful promoter for FP expression and VSFP expression, but expression off this promoter does not begin until P8-P9 in mouse subcortical and cortical areas (line 18, Stock No. 007612, The Jackson Laboratory; unpublished observations).

Another issue is ensuring appropriate expression levels that allow for optical monitoring of activity without interfering with normal development. The existence of only a few transgenic mouse lines expressing a GECI highlights the problem that getting high enough expression for optical monitoring is a challenge when using transgenic strategies. Therefore the most common methods of introducing GECI or VSFP transgenes have been by viral methodologies. Adenoviral vectors are the most common method of expressing indicators. Stable expression lasting weeks to months is reported, however it typically takes at least 7 days for high enough reporter expression for optical imaging experiments. This makes using this method unsuitable for fast developing model organisms like zebrafish. It also makes use of viral methods difficult for mice or rats, where embryonic introduction of the viral vector is necessary for studying the developing network activities taking place during the first postnatal week. Viral based transduction will be less problematic for model species such as ferrets or cats that have a protracted period of postnatal development and for which transgenic technologies are not feasible anyway. Also it is important to note that transgene expression with some viral vectors can have cytotoxic effects (Luo et al., 2008), which may significantly alter normal development.

\section{MANIPULATION OF NEURONAL ACTIVITY}

To understand the causative role that activity plays in sculpting neuronal circuits requires developing the capability to manipulate the spatiotemporal patterns of neural activity during development. Classical approaches to manipulate neural activity have focused on either blocking the sensory input (Wiesel and Hubel, 1965; Sretavan and Shatz, 1986), or changing neuronal firing properties by pharmacologically blocking or enhancing ion channels (Sretavan et al., 1988; Stellwagen et al., 1999). However, spontaneously occurring activity exists before the onset of sensory input in many circuits, such as the visual system, neuromuscular system, and the cerebellum. Moreover, pharmacological methods are non-specific in cell type and target location, making it difficult to decipher the precise role of specific pre- and post-synaptic activity patterns. In recent years, a number of genetic tools have become available that should prove very useful for studying the role of neural activity in circuit development.

Emerging genetic techniques have greatly overcome the drawbacks of traditional pharmacological approaches and brought new insights into anatomical and functional circuitry development. 
Genetic tools allow for spatial and temporal control over spontaneously occurring activity at the level of both network and individual cells (Bleckert and Wong, 2011). Expression of exogenous ion channel proteins, dominant negative forms, or disrupters/inhibitors of endogenous synaptic machinery have been used to examine the role of neural activity in the development of olfactory (Yu et al., 2004; Cao et al., 2007), visual (Hua et al., 2005; Kerschensteiner et al., 2009; Fredj et al., 2010), and cortical circuits (Mizuno et al., 2007, 2010; Wang et al., 2007; Yamada et al., 2010; De Marco García et al., 2011). The use of molecular genetic tools is an increasingly favored method for manipulating early neural activity patterns since transgenes can be delivered in vivo via electroporation, viral, or transgenic methodologies (Luo et al., 2008). For example, an elegant set of experiments in the zebrafish retinotectal system by Hua et al. (2005) demonstrated that in a competitive environment genetically silencing activity or blocking neurotransmitter release in a single retinal ganglion cell (RGC) results in a decrease in net growth and arbor complexity. In these experiments, they overexpressed Kir-2.1, an inward rectifying potassium channel, in RGCs via electroporation or using transgenic fish (Gal4/UAS system) to hyperpolarize RGCs and thus render them unable to fire action potentials. To suppress neurotransmitter release, by disrupting vesicle function, Hua et al. overexpressed a dominant negative for of vesicle associated membrane protein (VAMP) delivered in a similar manner as Kir-2.1. Another recent study in the zebrafish retinotectal system silenced RGC neurotransmitter release by overexpression of tetanus toxin (TeTx) light chain, which cleaves endogenous VAMP proteins and thus suppresses neurotransmitter release (Fredj et al., 2010).

Although genetic tools such as Kir-2.1, VAMP, and TeTx are convenient techniques for cell-specific suppression of both pre and post-activity during neural circuit development, they have certain caveats as the physiologic action of these manipulations are very different. Seemingly comparable manipulations can lead to different and contradictory results even within the same system. For example, suppression of neurotransmitter release using a dominant negative VAMP or TeTx can lead to opposing effects on axon arborization (Hua et al., 2005; Fredj et al., 2010). Moreover, manipulating activity in a small group of cells versus large populations can also have differential effects on circuit formation (Hua et al., 2005; Cao et al., 2007; Fredj et al., 2010).

\section{OPTICAL MANIPULATION OF NEURONAL ACTIVITY}

Francis Crick first suggested the use of light as a non-invasive way to control neuronal activities in a cell-type specific manner (Deisseroth, 2011). In the past decade, numerous tools have been developed that rely on light-sensitive molecules or proteins to optically control neural activity. For example, Lima and Miesenbock (2005) were able to achieve neural activation in Drosophila by using transgenic flies (Gal4-UAS system), a receptor-ligand system, and UV light. They expressed ATP gated ion channel $\mathrm{P}_{2} \mathrm{X}_{2}$, which upon activation depolarizes the cells and results in generation of action potentials, in a cell-type specific manner using different promoters. Light dependency of the system was achieved by attaching ATP to a photolabile group which could be "uncaged" by a flash of UV light. The combination of these various molecular parts enabled them to control neuronal activity, and thus induce behavioral changes in the flies. A similar approach has been successfully used in zebrafish to dissect and manipulate larval escape behavior using chemically modified light-gated ionotropic glutamate receptor LiGluR, which functions as a reversible photoswitch (Szobota et al., 2007).

However, there are drawbacks in these systems that make them unsuitable for achieving in vivo manipulation of activity in mammals. The dominant issue is poor temporal resolution, which is constrained by the timing in activation of receptors, since the temporal pattern of the pre- and post-synaptic activity is thought to provide critical information for circuit development (Katz and Shatz, 1996). Another drawback is accessibility, both in terms of light being able to uncage or alter protein configurations to allow ligands to bind to their receptors in deeper brain structures and to successfully deliver exogenous ligands to the desired tissue region.

\section{MANIPULATION OF NEURONAL ACTIVITY USING OPTOGENETICS}

Microbial opsin channels such as channelrhodopsin (ChR2), a light-sensitive cation channel from green algae, was first used to manipulate neural activity in mammalian hippocampal neurons (Boyden et al., 2005). ChR2 has a binding moiety for the lightsensitive all-trans retinal, which is present in vertebrate tissue, therefore no exogenous material is required. Blue light causes all-trans retinal to transform to an all-cis configuration, which opens the channel to depolarize the cell and trigger spiking activity. The dynamic time constant for the ChR2-induced photocurrent is about $200 \mu \mathrm{s}$, ensuring temporal precision in optical manipulations of spiking activity (Nagel et al., 2003). The use of ChR2, together with halorhodopsin (NpHR; Zhang et al., 2007) and other light-gated opsins to achieve light based control of neuronal activity, constitutes the now widely known "optogenetic" technique. Within the past few years, the optogenetics toolbox has expanded dramatically to include various engineered opsins with different functionalities and performance efficacies (Zhang et al., 2007, 2008; Lin et al., 2009; Chow et al., 2010), which have been summarized in several recent reviews (Gradinaru et al., 2010; Knöpfel et al., 2010; Hegemann and Moglich, 2011).

The expression of ChR2 in a desired brain region can be achieved by electroporation (Huber et al., 2008), viral transfection (Boyden et al., 2005; Zhang et al., 2007) as well as by using transgenic animals. In utero or in vivo electroporation enables timed expression of $\mathrm{ChR} 2 / \mathrm{NpHR}$ in specific cortical layers, which is a powerful tool in studying the subcellular organization of cortical circuitry (Petreanu et al., 2009) and potentially the development of cortical circuitry and projections. ChR2 has also been targeted to ON-bipolar cells using electroporation to induce visuomotor recovery in a mouse model of retinal degeneration (Lagali et al., 2008).

Viral constructs such as AAVs and lentivirus can be injected to defined nuclei in deep brain structures with anatomical precision (Gradinaru et al., 2009). Ectopic expression of ChR2 and $\mathrm{NpHR}$ in inner retinal neurons using AAV viral injection into the intravitreal space has restored $\mathrm{ON}$ and OFF light responses in the retina itself (Zhang et al., 2009). AAV-driven expression of $\mathrm{NpHR}$ in cone photoreceptors restored sophisticated retinal circuit functions, such as direction selectivity in Retinitis Pigmentosa mouse as well as ex vivo human retina (Busskamp et al., 
2010), demonstrating the potential medical application of this technique. However, the light intensity threshold for activation of ChR2 is much higher than that for intrinsic photoreceptors. An ultra light-sensitive $\mathrm{Ca}^{2+}$ permeable channelrhodopsin can potentially overcome this drawback (Kleinlogel et al., 2011). Moreover, delivery of AAV-double-floxed ChR2 into transgenic mice expressing Cre-recombinase in specific cell populations enables cell-type specific expression of ChR2 in fast-spiking interneurons (Cardin et al., 2009) and in starburst amacrine cells in the retina (Yonehara et al., 2011). These studies demonstrate roles for cell-type specificity in gamma oscillations in somatosensory cortex and the development of asymmetric inhibition in motion-sensitive retinal circuits. Other viral vectors, such as Sindbis and Rabies viruses have been used to express ChR2 in zebrafish (Zhu et al., 2009).

Optogenetic expression in transgenic vertebrate animals has been used successfully in both zebrafish and mice. Zebrafish is a convenient animal model for manipulating subpopulation of neurons in vivo using optogenetics, owing to the transparent optical access to brain tissue non-invasively. Expression of ChR2 (Douglass et al., 2008) and NpHR (Arrenberg et al., 2009) with behavioral control has been successful using the Gal4/UAS system in zebrafish. Using an enhancer element from the isl1 gene, ChR2 can also be expressed in trigeminal somatosensory neurons, whose single spike activity is at times sufficient to trigger escape behavior (Douglass et al., 2008). The kinetics of swimming behavior in zebrafish can be controlled by the high spatial and temporal resolution of ChR2 and eNpHR expression in the hindbrain (Arrenberg et al., 2009). The Tet system has also been used to drive ChR2 expression in zebrafish, although precise behavioral control has not been as reliable thus far (Zhu et al., 2009).

Transgenic mice with ChR2 expression are available under various promoters such as Thyl (Arenkiel et al., 2007), Chat (Ren et al., 2011), VGAT2 (Halassa et al., 2011), and parvalbumin (Jackson Laboratory). Cell-type specific activation in mice expressing ChR2 has lead to several novel insights: traditionally defined Habenula cholinergic neurons not only release acetylcholine but also glutamate (Ren et al., 2011) and selective activation of the thalamic reticular nucleus generates thalamic bursting activity and cortical spindles (Halassa et al., 2011). There are limits to this approach, however. The expression of ChR2 in RGCs under control of the Thyl promoter could not restore visual response in mice which lacked most photoreceptors (Thyagarajan et al., 2010), presumably because ChR2 expression was too low or too insensitive to normal light levels.

\section{MANIPULATION OF ACTIVITY IN DEVELOPING NEURAL CIRCUITS}

As evidenced by the studies discussed above, optogenetic tools have predominantly been used to probe network connectivity and function in already established circuits. ChR2 has also been used to manipulate spinal motor activity in developing chick embryos, thus illustrating a role for patterned activity in axon pathfinding for motor neurons (Kastanenka and Landmesser, 2010). However, manipulating activity during development does present some key challenges that must be overcome for optogenetic techniques to be employed fully by researchers studying the basis of activity-dependent neural circuit formation.
One of these key challenges facing the use of optogenetics in manipulating developmental activity patterns is that the expression of activity-modulating proteins needs to be turned on early enough during the window of embryonic or postnatal development being studied. Different transfection methods take different amounts of time for the expression to reach a threshold level for activity manipulation. Electroporation of targeted regions in utero or postnatally typically enables quick expression of transgenes within 1-2 days, but requires invasive surgery and access to a fluid space immediately adjacent to the targeted cell population (e.g., vitreous of the eye or ventricles of the brain). Viral based transduction methods can result in stable expression levels of transgenes in a potentially larger population of cells, but requires a longer time (5-7 days) for detectable expression. Many new transgenic animal lines expressing some of the most widely used activitymanipulation genes are under development. Some of the new lines that will become available, such as floxed-ChR2 mice, will be combined powerfully with CRE mice lines, resulting in expression of these proteins in specific cell types that will enable targeted manipulation of neural circuit activity. However, it will be critical to carefully choose promoters that allows for spatially and temporally appropriate expression levels in developmental studies.

Chronic experiments for activity manipulation in rodents will also be challenging due to the logistical difficulties working with small neonates and minimizing the developmental impact of altered nursing behavior. For optogenetic based approaches, fiberoptic based stimulation techniques (Aravanis et al., 2007; Knöpfel et al., 2010) are invasive to neonates and have potential difficulties associated with long-term manipulations while the brain and body are undergoing dramatic growth. Moreover, the fiber-optic will need to be miniaturized and probably detachable for nursing periods.

Chemical-genetic methods have been recently developed to control overall neural activity levels when temporal precision is not necessary. These methods could be applied to the study of neural circuit development. Unlike optogenetic techniques, which require the chronic implant of optical fibers, chemical-genetic methods usually involve cell-type or region-specific expression of modified receptors or channels such as $\mathrm{GABA}_{\mathrm{A}}$ receptors (Wulff et al., 2007), G-protein coupled receptors (Alexander et al., 2009), $\mathrm{Cl}^{-}$channels (Lerchner et al., 2007) and various ligand-gated ion channels (Magnus et al., 2011), together with the injection of corresponding pharmacological agents. A few hours after the injection, behavioral correlates of neural activity changes can be observed (Lerchner et al., 2007; Wulff et al., 2007; Alexander et al., 2009). What is more, some of these manipulations are reversible, which enables selective manipulation of activity at a particular stage of development.

\section{SUMMARY}

Functional neural circuits arise from patterned gene expression and neuronal activity during development. Since many neurological disorders likely proceed from an altered balance between intrinsic and extrinsic factors that impact neural circuit development, it is crucial to describe the patterned neuronal activities experienced by developing neurons and the precise role that these patterns play in functional circuit formation. Many recent advances in molecular genetic methods have made experiments 
concerning the visualization and manipulation of neuronal activity feasible. However, crucial challenges do remain in fully applying these technologies to studies of brain development, with a primary one being how to express the appropriate transgene in the right place at the right time in the constantly shifting genetic landscape of the immature nervous system. Further characterization

\section{REFERENCES}

Ackman, J. B., Aniksztejn, L., Crepel, V., Becq, H., Pellegrino, C., Cardoso, C., Ben-Ari, Y., and Represa, A. (2009). Abnormal network activity in a targeted genetic model of human double cortex. J. Neurosci. 29, 313-327.

Alexander, G. M., Rogan, S. C., Abbas, A. I., Armbruster, B. N., Pei, Y., Allen, J. A., Nonneman, R. J., Hartmann, J., Moy, S. S., Nicolelis, M. A., McNamara, J. O., and Roth, B. L. (2009). Remote control of neuronal activity in transgenic mice expressing evolved G protein-coupled receptors. Neuron 63, 27-39.

Allene, C., Cattani, A., Ackman, J. B., Bonifazi, P., Aniksztejn, L., Ben-Ari, Y., and Cossart, R. (2008). Sequential generation of two distinct synapsedriven network patterns in developing neocortex. J. Neurosci. 28, 12851-12863.

Andermann, M. L., Kerlin, A. M., and Reid, R. C. (2010). Chronic cellular imaging of mouse visual cortex during operant behavior and passive viewing. Front. Cell. Neurosci. 4:3. doi:10.3389/fncel.2010.00003

Aravanis, A. M., Wang, L.-P., Zhang, F., Meltzer, L. A., Mogri, M. Z., Schneider, B. M., and Deisseroth, K. (2007). An optical neural interface: in vivo control of rodent motor cortex with integrated fiberoptic and optogenetic technology. J. Neural Eng. 4, S143.

Arenkiel, B. R., Peca, J., Davison, I. G., Feliciano, C., Deisseroth, K., Augustine, G. J., Ehlers, M. D., and Feng, G. (2007). In vivo light-induced activation of neural circuitry in transgenic mice expressing channelrhodopsin2. Neuron 54, 205-218.

Arrenberg, A. B., Del Bene, F., and Baier, H. (2009). Optical control of zebrafish behavior with halorhodopsin. Proc. Natl. Acad. Sci. U.S.A. 106, 17968-17973.

Benucci, A., Frazor, R. A., and Carandini, M. (2007). Standing waves and traveling waves distinguish two circuits in visual cortex. Neuron 55, 103-117.

Blankenship, A. G., and Feller, M. B. (2010). Mechanisms underlying spontaneous patterned activity in developing neural circuits. Nat. Rev. Neurosci. 11, 18-29.
Bleckert, A., and Wong, R. O. (2011). Identifying roles for neurotransmission in circuit assembly: insights gained from multiple model systems and experimental approaches. Bioessays 33, 61-72.

Bonhoeffer, T., and Grinvald, A. (1991). Iso-orientation domains in cat visual cortex are arranged in pinwheel-like patterns. Nature 353, 429-431.

Bonifazi, P., Goldin, M., Picardo, M. A., Jorquera, I., Cattani, A., Bianconi, G., Represa, A., Ben-Ari, Y., and Cossart, R. (2009). GABAergic hub neurons orchestrate synchrony in developing hippocampal networks. Science 326, 1419-1424.

Bossert, J. M., Stern, A. L., Theberge, F. R. M., Cifani, C., Koya, E., Hope, B. T., and Shaham, Y. (2011). Ventral medial prefrontal cortex neuronal ensembles mediate context-induced relapse to heroin. Nat. Neurosci. 14, 420-422.

Boyden, E. S., Zhang, F., Bamberg, E., Nagel, G., and Deisseroth, K. (2005). Millisecond-timescale, genetically targeted optical control of neural activity. Nat. Neurosci. 8, 1263-1268.

Busskamp, V., Duebel, J., Balya, D., Fradot, M., Viney, T. J., Siegert, S., Groner, A. C., Cabuy, E., Forster, V. R., Seeliger, M., Biel, M., Humphries, P., Paques, M., Mohand-Said, S., Trono, D., Deisseroth, K., Sahel, J. A., Picaud, S., and Roska, B. (2010). Genetic reactivation of cone photoreceptors restores visual responses in retinitis pigmentosa. Science 329, 413-417.

Butts, D. A., Kanold, P. O., and Shatz, C. J. (2007). A burst-based "Hebbian" learning rule at retinogeniculate synapses links retinal waves to activity-dependent refinement. PLoS Biol. 5, e61. doi:10.1371/journal.pbio.0050061

Cang, J., Rentería, R. C., Kaneko, M., Liu, X., Copenhagen, D. R., and Stryker, M. P. (2005). Development of precise maps in visual cortex requires patterned spontaneous activity in the retina. Neuron 48, 797-809.

Cao, L., Dhilla, A., Mukai, J., Blazeski, R., Lodovichi, C., Mason, C. A., and Gogos, J. A. (2007). Genetic modulation of BDNF signaling affects

of the animal lines being produced by several ongoing large-scale transgenic mouse screening efforts will be essential in identifying cell specific and time specific genetic promoters that can be utilized for these endeavors. We will soon be in a position in which we may examine precisely how activity-dependent development effects functional circuit organization.

the outcome of axonal competition in vivo. Curr. Biol. 17, 911-921.

Cardin, J. A., Carlen, M., Meletis, K., Knoblich, U., Zhang, F., Deisseroth, K., Tsai, L.-H., and Moore, C. I. (2009). Driving fast-spiking cells induces gamma rhythm and controls sensory responses. Nature 459, 663-667.

Chaigneau, E., Tiret, P., Lecoq, J., Ducros, M., Knöpfel, T., and Charpak, S. (2007). The relationship between blood flow and neuronal activity in the rodent olfactory bulb. J. Neurosci. 27, 6452-6460.

Chalasani, S. H., Chronis, N., Tsunozaki, M., Gray, J. M., Ramot, D., Goodman, M. B., and Bargmann, C. I. (2007). Dissecting a circuit for olfactory behaviour in Caenorhabditis elegans. Nature 450, 63-70.

Chapman, B., Stryker, M. P., and Bonhoeffer, T. (1996). Development of orientation preference maps in ferret primary visual cortex. J. Neurosci. 16, 6443-6453.

Chow, B. Y., Han, X., Dobry, A. S., Qian, X., Chuong, A. S., Li, M., Henninger, M. A., Belfort, G. M., Lin, Y., Monahan, P. E., and Boyden, E. S. (2010). High-performance genetically targetable optical neural silencing by light-driven proton pumps. Nature 463, 98-102.

Cohen, L. B., Keynes, R. D., and Hille, B. (1968). Light scattering and birefringence changes during nerve activity. Nature 218, 438-441.

Cohen, L. B., Salzberg, B. M., and Grinvald, A. (1978). Optical methods for monitoring neuron activity. Annu. Rev. Neurosci. 1, 171-182.

Cossart, R., Aronov, D., and Yuste, R. (2003). Attractor dynamics of network UP states in the neocortex. Nature 423, 283-288.

Cossart, R., Ikegaya, Y., and Yuste, R. (2005). Calcium imaging of cortical networks dynamics. Cell Calcium 37, 451-457.

Crair, M. C., Gillespie, D. C., and Stryker, M. P. (1998). The role of visual experience in the development of columns in cat visual cortex. Science 279, 566-570.

Crépel, V., Aronov, D., Jorquera, I., Represa, A., Ben-Ari, Y., and Cossart, R. (2007). A parturitionassociated nonsynaptic coherent activity pattern in the developing hippocampus. Neuron 54, 105-120.

Davila, H. V., Salzberg, B. M., Cohen, L. B., and Waggoner, A. S. (1973). A large change in axon fluorescence that provides a promising method for measuring membrane potential. Nat. New Biol. 241, 159-160.

De Marco García, N. V., Karayannis, T., and Fishell, G. (2011). Neuronal activity is required for the development of specific cortical interneuron subtypes. Nature 472, 351-355.

Deisseroth, K. (2011). Optogenetics. Nat. Methods 8, 26-29.

Díez-García, J., Akemann, W., and Knöpfel, T. (2007). In vivo calcium imaging from genetically specified target cells in mouse cerebellum. Neuroimage 34, 859-869.

Djurisic, M., Antic, S., Chen, W. R., and Zecevic, D. (2004). Voltage imaging from dendrites of mitral cells: EPSP attenuation and spike trigger zones. J. Neurosci. 24, 6703-6714.

Dombeck, D. A., Graziano, M. S., and Tank, D. W. (2009). Functional clustering of neurons in motor cortex determined by cellular resolution imaging in awake behaving mice. J. Neurosci. 29, 13751-13760.

Douglass, A. D., Kraves, S., Deisseroth, K., Schier, A. F., and Engert, F. (2008). Escape behavior elicited by single, channelrhodopsin-2-evoked spikes in zebrafish somatosensory neurons. Curr. Biol. 18, 1133-1137.

Feller, M. B. (1999). Spontaneous correlated activity in developing neural circuits. Neuron 22, 653-656.

Ferezou, I., Bolea, S., and Petersen, C. C. H. (2006). Visualizing the cortical representation of whisker touch: voltage-sensitive dye imaging in freely moving mice. Neuron 50, 617-629.

Flavell, S. W., and Greenberg, M. E. (2008). Signaling mechanisms linking neuronal activity to gene expression and plasticity of the nervous system. Annu. Rev. Neurosci. 31, 563-590.

Fletcher, M. L., Masurkar, A. V., Xing, J., Imamura, F., Xiong, W., Nagayama, S., Mutoh, H., Greer, C. A., Knöpfel, T., and Chen, W. R. (2009). Optical imaging of postsynaptic odor representation in the glomerular layer of the mouse olfactory bulb. J. Neurophysiol. 102, 817-830. 
Fredj, N. B., Hammond, S., Otsuna, H., Chien, C.-B., Burrone, J., and Meyer, M. P. (2010). Synaptic activity and activity-dependent competition regulates axon arbor maturation, growth arrest, and territory in the retinotectal projection. J. Neurosci. 30, 10939-10951.

Garaschuk, O., Linn, J., Eilers, J., and Konnerth, A. (2000). Large-scale oscillatory calcium waves in the immature cortex. Nat. Neurosci. 3, 452-459.

Gjorgjieva, J., Toyoizumi, T., and Eglen, S. J. (2009). Burst-timedependent plasticity robustly guides ON/OFF segregation in the lateral geniculate nucleus. PLoS Comput. Biol. 5, e1000618. doi:10.1371/journal.pcbi.1000618

Gradinaru, V., Mogri, M., Thompson, K. R., Henderson, J. M., and Deisseroth, K. (2009). Optical deconstruction of parkinsonian neural circuitry. Science 324, 354-359.

Gradinaru, V., Zhang, F., Ramakrishnan, C., Mattis, J., Prakash, R., Diester, I., Goshen, I., Thompson, K. R., and Deisseroth, K. (2010). Molecular and cellular approaches for diversifying and extending optogenetics. Cell 141, 154-165.

Greenberg, D. S., Houweling, A. R., and Kerr, J. N. D. (2008). Population imaging of ongoing neuronal activity in the visual cortex of awake rats. Nat. Neurosci. 11, 749-751.

Grinvald, A., Anglister, L., Freeman, J. A., Hildesheim, R., and Manker, A. (1984). Real-time optical imaging of naturally evoked electrical activity in intact frog brain. Nature 308, 848-850.

Grinvald, A., and Hildesheim, R. (2004). VSDI: a new era in functional imaging of cortical dynamics. Nat. Rev. Neurosci. 5, 874-885.

Guzowski, J. F., Timlin, J. A., Roysam, B., McNaughton, B. L., Worley, P. F., and Barnes, C. A. (2005). Mapping behaviorally relevant neural circuits with immediate-early gene expression. Curr. Opin. Neurobiol. 15, 599-606.

Halassa, M. M., Siegle, J. H., Ritt, J. T., Ting, J. T., Feng, G., and Moore, C. I. (2011). Selective optical drive of thalamic reticular nucleus generates thalamic bursts and cortical spindles. Nat. Neurosci. 14, 1118-1120.

Han, F., Caporale, N., and Dan, Y. (2008). Reverberation of recent visual experience in spontaneous cortical waves. Neuron 60, 321-327.

Hegemann, P., and Moglich, A. (2011). Channelrhodopsin engineering and exploration of new optogenetic tools. Nat. Methods 8, 39-42.

Heim, N., Garaschuk, O., Friedrich, M. W., Mank, M., Milos, R. I., Kovalchuk, Y., Konnerth, A., and Griesbeck, O. (2007). Improved calcium imaging in transgenic mice expressing a troponin C-based biosensor. Nat. Methods 4, 127-129.

Heim, N., and Griesbeck, O. (2004). Genetically encoded indicators of cellular calcium dynamics based on troponin $\mathrm{C}$ and green fluorescent protein. J. Biol. Chem. 279, 14280-14286.

Higashijima, S.-I., Masino, M. A., Mandel, G., and Fetcho, J. R. (2003). Imaging neuronal activity during zebrafish behavior with a genetically encoded calcium indicator. $J$. Neurophysiol. 90, 3986-3997.

Hill, D. K., and Keynes, R. D. (1949). Opacity changes in stimulated nerve. J. Physiol. (Lond.) 108, 278-281.

Hua, J. Y., Smear, M. C., Baier, H., and Smith, S. J. (2005). Regulation of axon growth in vivo by activity-based competition. Nature 434, 1022-1026.

Huber, D., Petreanu, L., Ghitani, N., Ranade, S., Hromadka, T., Mainen, Z., and Svoboda, K. (2008). Sparse optical microstimulation in barrel cortex drives learned behaviour in freely moving mice. Nature 451, 61-64.

Ikegaya, Y., Aaron, G., Cossart, R., Aronov, D., Lampl, I., Ferster, D., and Yuste, R. (2004). Synfire chains and cortical songs: temporal modules of cortical activity. Science 304, 559-564.

Jayaraman, V., and Laurent, G. (2007). Evaluating a genetically encoded optical sensor of neural activity using electrophysiology in intact adult fruit flies. Front. Neural Circuits 1:3. doi:10.3389/neuro.04/003.2007

Kastanenka, K. V., and Landmesser, L. T. (2010). In vivo activation of channelrhodopsin-2 reveals that normal patterns of spontaneous activity are required for motoneuron guidance and maintenance of guidance molecules. J. Neurosci. 30, 10575-10585.

Katz, L. C., and Shatz, C. J. (1996). Synaptic activity and the construction of cortical circuits. Science 274, 1133-1138.

Kauer, J. S. (1988). Real-time imaging of evoked activity in local circuits of the salamander olfactory bulb. Nature 331, 166-168.
Kerr, J. N. D., Greenberg, D., and Helmchen, F. (2005). Imaging input and output of neocortical networks in vivo. Proc. Natl. Acad. Sci. U.S.A. 102, 14063-14068.

Kerr, R., Lev-Ram, V., Baird, G., Vincent, P., Tsien, R. Y., and Schafer, W. R. (2000). Optical imaging of calcium transients in neurons and pharyngeal muscle of C. elegans. Neuron 26 , 583-594.

Kerschensteiner, D., Morgan, J. L., Parker, E. D., Lewis, R. M., and Wong, R. O. L. (2009). Neurotransmission selectively regulates synapse formation in parallel circuits in vivo. Nature 460, 1016-1020.

Kleinlogel, S., Feldbauer, K., Dempski, R. E., Fotis, H., Wood, P. G., Bamann, C., and Bamberg, E. (2011). Ultra light-sensitive and fast neuronal activation with the $\mathrm{Ca} 2+-$ permeable channelrhodopsin CatCh. Nat. Neurosci. 14, 513-518.

Knöpfel, T., Lin, M. Z., Levskaya, A., Tian, L., Lin, J. Y., and Boyden, E. S. (2010). Toward the second generation of optogenetic tools. J. Neurosci. 30, 14998-15004.

Koya, E., Golden, S. A., Harvey, B. K., Guez-Barber, D. H., Berkow, A., Simmons, D. E., Bossert, J. M., Nair, S. G., Uejima, J. L., Marin, M. T., Mitchell, T. B., Farquhar, D., Ghosh, S. C., Mattson, B. J., and Hope, B. T. (2009). Targeted disruption of cocaine-activated nucleus accumbens neurons prevents contextspecific sensitization. Nat. Neurosci. 12, 1069-1073.

Kuchibhotla, K. V., Lattarulo, C. R. Hyman, B. T., and Bacskai, B. J. (2009). Synchronous hyperactivity and intercellular calcium waves in astrocytes in Alzheimer mice. Science 323, 1211-1215.

Lagali, P. S., Balya, D., Awatramani, G. B. Munch, T. A., Kim, D. S., Busskamp, V., Cepko, C. L., and Roska, B. (2008). Light-activated channels targeted to $\mathrm{ON}$ bipolar cells restore visual function in retinal degeneration. Nat. Neurosci. 11, 667-675.

Lerchner, W., Xiao, C., Nashmi, R. Slimko, E. M., van Trigt, L., Lester, H. A., and Anderson, D. J. (2007). Reversible silencing of neuronal excitability in behaving mice by a genetically targeted, ivermectingated Cl- channel. Neuron 54, 35-49.

Lieke, E. E., Frostig, R. D., Arieli, A., Ts'o, D. Y., Hildesheim, R., and Grinvald, A. (1989). Optical imaging of cortical activity: real-time imaging using extrinsic dye-signals and high resolution imaging based on slow intrinsic-signals. Annu. Rev. Physiol. 51, 543-559.

Lima, S. Q., and Miesenbock, G. (2005). Remote control of behavior through genetically targeted photostimulation of neurons. Cell 121, 141-152.

Lin, J. Y., Lin, M. Z., Steinbach, P. and Tsien, R. Y. (2009). Characterization of engineered channelrhodopsin variants with improved properties and kinetics. Biophys. J. 96, 1803-1814.

Loebrich, S., and Nedivi, E. (2009). The function of activity-regulated genes in the nervous system. Physiol. Rev. 89, 1079-1103.

Luo, L., Callaway, E. M., and Svoboda, K. (2008). Genetic dissection of neural circuits. Neuron 57, 634-660.

Lütcke, H., Murayama, M., Hahn, T., Margolis, D. J., Astori, S., Zum Alten Borgloh, S. M., Göbel, W., Yang, Y., Tang, W., Kügler, S., Sprengel, R., Nagai, T., Miyawaki, A., Larkum, M. E., Helmchen, F., and Hasan, M. T. (2010). Optical recording of neuronal activity with a genetically-encoded calcium indicator in anesthetized and freely moving mice. Front. Neural Circuits 4:9. doi:10.3389/fncir.2010.00009

Magnus, C. J., Lee, P. H., Atasoy, D., Su, H. H., Looger, L. L., and Sternson, S. M. (2011). Chemical and genetic engineering of selective ion channel-ligand interactions. Science 333, 1292-1296.

Mank, M., Santos, A., Direnberger, S., Mrsic-Flogel, T., Hofer, S., Stein V., Hendel, T., Reiff, D., Levelt, C., Borst, A., Bonhoeffer, T., Hubener, M., and Griesbeck, O. (2008). A genetically encoded calcium indicator for chronic in vivo two-photon imaging. Nat. Methods 5, 805-811.

Miyawaki, A., Llopis, J., Heim, R., McCaffery, J. M., Adams, J. A., Ikura, M., and Tsien, R. Y. (1997). Fluorescent indicators for $\mathrm{Ca} 2+$ based on green fluorescent proteins and calmodulin. Nature 388, 882-887.

Mizuno, H., Hirano, T., and Tagawa, Y. (2007). Evidence for activitydependent cortical wiring: formation of interhemispheric connections in neonatal mouse visual cortex requires projection neuron activity. J. Neurosci. 27, 6760-6770.

Mizuno, H., Hirano, T., and Tagawa, Y. (2010). Pre-synaptic and postsynaptic neuronal activity supports the axon development of callosal projection neurons during different post-natal periods in the mouse cerebral cortex. Eur. J. Neurosci. 31, 410-424. 
Mrsic-Flogel, T. D., Hofer, S. B., Creutzfeldt, C., Cloez-Tayarani, I., Changeux, J.-P., Bonhoeffer, T., and Hubener, M. (2005). Altered map of visual space in the superior colliculus of mice lacking early retinal waves. J. Neurosci. 25, 6921-6928.

Nagai, T., Yamada, S., Tominaga, T., Ichikawa, M., and Miyawaki, A. (2004). Expanded dynamic range of fluorescent indicators for $\mathrm{Ca}(2+)$ by circularly permuted yellow fluorescent proteins. Proc. Natl. Acad. Sci. U.S.A. 101, 10554-10559.

Nagel, G., Szellas, T., Huhn, W., Kateriya, S., Adeishvili, N., Berthold, P., Ollig, D., Hegemann, P., and Bamberg, E. (2003). Channelrhodopsin-2, a directly light-gated cation-selective membrane channel. Proc. Natl. Acad. Sci. U.S.A. 100, 13940-13945.

O'Donovan, M. J. (1999). The origin of spontaneous activity in developing networks of the vertebrate nervous system. Curr. Opin. Neurobiol. 9, 94-104.

Ohki, K., Chung, S., Ch'ng, Y. H., Kara, P., and Reid, R. C. (2005). Functional imaging with cellular resolution reveals precise micro-architecture in visual cortex. Nature 433, 597-603.

Orbach, H. S., and Cohen, L. B. (1983). Optical monitoring of activity from many areas of the in vitro and in vivo salamander olfactory bulb: a new method for studying functional organization in the vertebrate central nervous system. J. Neurosci. 3, 2251-2262.

Orbach, H. S., Cohen, L. B., and Grinvald, A. (1985). Optical mapping of electrical activity in rat somatosensory and visual cortex. J. Neurosci. 5, 1886-1895.

Petreanu, L., Mao, T., Sternson, S. M., and Svoboda, K. (2009). The subcellular organization of neocortical excitatory connections. Nature 457, 1142-1145.

Regehr, W. G., Connor, J. A., and Tank, D. W. (1989). Optical imaging of calcium accumulation in hippocampal pyramidal cells during synaptic activation. Nature 341, 533-536.

Ren, J., Qin, C., Hu, F., Tan, J., Qiu, L., Zhao, S., Feng, G., and Luo, M. (2011). Habenula "Cholinergic" neurons corelease glutamate and acetylcholine and activate postsynaptic neurons via distinct transmission modes. Neuron 69, 445-452.

Rubin, B. D., and Katz, L. C. (1999). Optical imaging of odorant representations in the mammalian olfactory bulb. Neuron 23, 499-511.
Shoham, D., Glaser, D. E., Arieli, A., Kenet, T., Wijnbergen, C., Toledo, Y., Hildesheim, R., and Grinvald, A. (1999). Imaging cortical dynamics at high spatial and temporal resolution with novel blue voltage-sensitive dyes. Neuron 24, 791-802.

Sjulson, L., and Miesenböck, G. (2007). Optical recording of action potentials and other discrete physiological events: a perspective from signal detection theory. Physiology (Bethesda) 22, 47-55.

Smetters, D., Majewska, A., and Yuste, R. (1999). Detecting action potentials in neuronal populations with calcium imaging. Methods 18, 215-221.

Spitzer, N. C. (2006). Electrical activity in early neuronal development. Nature 444, 707-712.

Spors, H., and Grinvald, A. (2002). Spatio-temporal dynamics of odor representations in the mammalian olfactory bulb. Neuron 34, 301-315.

Sretavan, D. W., and Shatz, C. J. (1986). Prenatal development of cat retinogeniculate axon arbors in the absence of binocular interactions. J. Neurosci. 6, 990-1003.

Sretavan, D. W., Shatz, C. J., and Stryker, M. P. (1988). Modification of retinal ganglion cell axon morphology by prenatal infusion of tetrodotoxin. Nature 336, 468-471.

Stellwagen, D., Shatz, C. J., and Feller, M. B. (1999). Dynamics of retinal waves are controlled by cyclic AMP. Neuron 24, 673-685.

Stosiek, C., Garaschuk, O., Holthoff, K., and Konnerth, A. (2003). In vivo two-photon calcium imaging of neuronal networks. Proc. Natl. Acad. Sci. U.S.A. 100, 7319-7324.

Sutor, B., Hablitz, J. J., Rucker, F., and ten Bruggencate, G. (1994). Spread of epileptiform activity in the immature rat neocortex studied with voltage-sensitive dyes and laser scanning microscopy. J. Neurophysiol. 72, 1756-1768.

Szobota, S., Gorostiza, P., Del Bene, F., Wyart, C., Fortin, D. L., Kolstad, K. D., Tulyathan, O., Volgraf, M., Numano, R., Aaron, H. L., Scott, E. K., Kramer, R. H., Flannery, J., Baier, H., Trauner, D., and Isacoff, E. Y. (2007). Remote control of neuronal activity with a light-gated glutamate receptor. Neuron 54, 535-545.

Tallini, Y. N., Ohkura, M., Choi, B.-R., Ji, G., Imoto, K., Doran, R., Lee, J., Plan, P., Wilson, J., Xin, H.-B., Sanbe, A., Gulick, J., Mathai, J., Robbins, J., Salama, G., Nakai, J., and Kotlikoff, M. I. (2006). Imaging cellular signals in the heart in vivo: cardiac expression of the high-signal $\mathrm{Ca} 2+$ indicator GCaMP2. Proc. Natl. Acad. Sci. U.S.A. 103, 4753-4758.

Tasaki, I., Watanabe, A., Sandlin, R., and Carnay, L. (1968). Changes in fluorescence, turbidity, and birefringence associated with nerve excitation. Proc. Natl. Acad. Sci. U.S.A. 61, 883-888.

Thyagarajan, S., van Wyk, M., Lehmann, K., Lawel, S., Feng, G., and Wässle, H. (2010). Visual function in mice with photoreceptor degeneration and transgenic expression of channelrhodopsin 2 in ganglion cells. J. Neurosci. 30, 8745-8758.

Tian, C., Bagley, J., Kaye, J., and Iacomini, J. (2003). Induction of T cell tolerance to a protein expressed in the cytoplasm through retroviralmediated gene transfer. J. Gene Med. 5, 359-365.

Tritsch, N. X., Yi, E., Gale, J. E., Glowatzki, E., and Bergles, D. E. (2007). The origin of spontaneous activity in the developing auditory system. Nature 450, 50-55.

Tsien, R. Y. (1989). Fluorescent probes of cell signaling. Annu. Rev. Neurosci. 12, 227-253.

Ts'o, D. Y., Frostig, R. D., Lieke, E. E., and Grinvald, A. (1990). Functional organization of primate visual cortex revealed by high resolution optical imaging. Science 249, 417-420.

von Muralt, A. (1975). The optical spike. Philos. Trans. R. Soc. Lond. B Biol. Sci. 270, 411-423.

Wang, C.-L., Zhang, L., Zhou, Y., Zhou, J., Yang, X.-J., Duan, S.M., Xiong, Z.-Q., and Ding, Y.-Q. (2007). Activity-dependent development of callosal projections in the somatosensory cortex. J. Neurosci. 27, 11334-11342.

Wang, J. W., Wong, A. M., Flores, J., Vosshall, L. B., and Axel, R. (2003). Two-photon calcium imaging reveals an odor-evoked map of activity in the fly brain. Cell 112, 271-282.

Wang, K. H., Majewska, A., Schummers, J., Farley, B., Hu, C., Sur, M., and Tonegawa, S. (2006). In vivo twophoton imaging reveals a role of arc in enhancing orientation specificity in visual cortex. Cell 126, 389-402.

Wiesel, T. N., and Hubel, D. H. (1965). Comparison of the effects of unilateral and bilateral eye closure on cortical unit responses in kittens. $J$. Neurophysiol. 28, 1029-1040.

Wulff, P., Goetz, T., Leppä, E., Linden, A.-M., Renzi, M., Swinny, J. D., Vekovischeva, O. Y., Sieghart, W., Somogyi, P., Korpi, E. R., Farrant,
M., and Wisden, W. (2007). From synapse to behavior: rapid modulation of defined neuronal types with engineered GABAA receptors. Nat. Neurosci. 10, 923-929.

Xu, W., Huang, X., Takagaki, K., and Wu, J.-Y. (2007). Compression and reflection of visually evoked cortical waves. Neuron 55, 119-129.

Yamada, A., Uesaka, N., Hayano, Y., Tabata, T., Kano, M., and Yamamoto, N. (2010). Role of pre- and postsynaptic activity in thalamocortical axon branching. Proc. Natl. Acad. Sci. U.S.A. 107, 7562-7567.

Yassin, L., Benedetti, B. L., Jouhanneau, J.-S., Wen, J. A., Poulet, J. F. A., and Barth, A. L. (2010). An embedded subnetwork of highly active neurons in the neocortex. Neuron 68, 1043-1050.

Yonehara, K., Balint, K., Noda, M., Nagel, G., Bamberg, E., and Roska, B. (2011). Spatially asymmetric reorganization of inhibition establishes a motion-sensitive circuit. Nature 469, 407-410.

Yu, C. R., Power, J., Barnea, G., O'Donnell, S., Brown, H. E. V., Osborne, J., Axel, R., and Gogos, J. A. (2004). Spontaneous neural activity is required for the establishment and maintenance of the olfactory sensory map. Neuron 42, 553-566.

Yuste, R., and Katz, L. C. (1991). Control of postsynaptic $\mathrm{Ca} 2+$ influx in developing neocortex by excitatory and inhibitory neurotransmitters. $\mathrm{Neu}$ ron 6, 333-344.

Yuste, R., Nelson, D. A., Rubin, W. W., and Katz, L. C. (1995). Neuronal domains in developing neocortex: mechanisms of coactivation. Neuron 14, 7-17.

Zhang, F., Prigge, M., Beyriere, F., Tsunoda, S. P., Mattis, J., Yizhar, O., Hegemann, P., and Deisseroth, K. (2008). Red-shifted optogenetic excitation: a tool for fast neural control derived from Volvox carteri. Nat. Neurosci. 11, 631-633.

Zhang, F., Wang, L.-P., Brauner, M., Liewald, J. F., Kay, K., Watzke, N., Wood, P. G., Bamberg, E., Nagel G., Gottschalk, A., and Deisseroth, K. (2007). Multimodal fast optical interrogation of neural circuitry. Nature 446, 633-639.

Zhang, Y., Ivanova, E., Bi, A., and Pan, Z.-H. (2009). Ectopic expression of multiple microbial rhodopsins restores $\mathrm{ON}$ and OFF light responses in retinas with photoreceptor degeneration. J. Neurosci. 29, 9186-9196.

Zhu, P., Narita, Y., Bundschuh, S. T., Fajardo, O., Zhang Schoerer, Y.-P., Chattopadhyaya, B., Arn Bouldoires, 
E., Stepien, A. E., Deisseroth, K., Arber, S., Sprengel, R., Rijli, F. M., and Friedrich, R. W. (2009). Optogenetic dissection of neuronal circuits in zebrafish using viral gene transfer and the Tet system. Front. Neural Circuits 3:21. doi:10.3389/neuro.04.021. 2009
Conflict of Interest Statement: The authors declare that the research was conducted in the absence of any commercial or financial relationships that could be construed as a potential conflict of interest.

Received: 16 September 2011; paper pending published: 05 October 2011; accepted: 30 October 2011; published online: 18 November 2011.

Citation: Zhang J, Ackman JB, Dhande OS and Crair MC (2011) Visualization and manipulation of neural activity in the developing vertebrate nervous system. Front. Mol. Neurosci. 4:43. doi: 10.3389/fnmol.2011. 00043
Copyright (C) 2011 Zhang, Ackman, Dhande and Crair. This is an open-acces article subject to a non-exclusive license between the authors and Frontiers Media $S A$, which permits use, distribution and reproduction in other forums, provided the original authors and source are credited and other Frontiers conditions are complied with. 